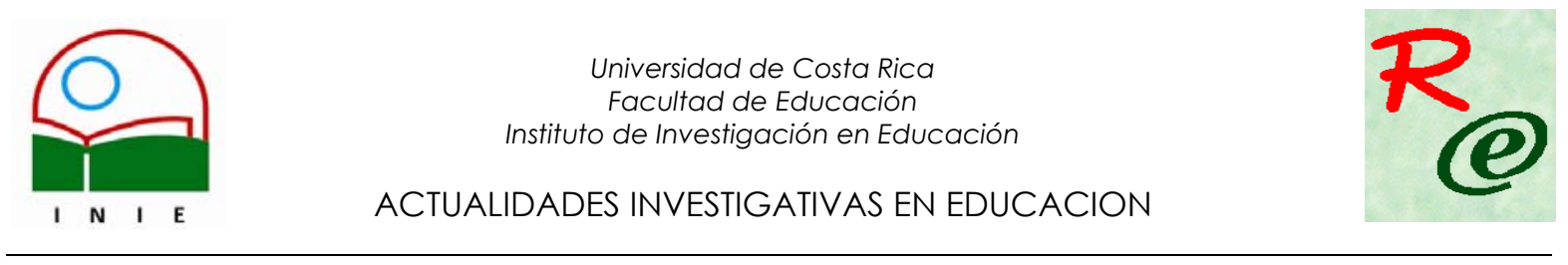

\title{
SOFTWARE LIBRE, ALTERNATIVA TECNOLÓGICA PARA LA EDUCACIÓN
}

\begin{abstract}
Johnny Valverde Chavarría ${ }^{1}$
Resumen: Interesa conocer la utilización práctica del software libre en ámbitos educativos; especialmente se enfatiza en cómo este se puede convertir en una herramienta apropiada para los procesos de enseñanza y aprendizaje, aunque sin soslayar sus características ventajosas y menos ventajosas, considerando los contextos en que se ponga en marcha. Además, se dan ejemplos prácticos de su utilización. Se incorporan algunas noticias de eventos y hechos relevantes de reciente suceso para ilustrar más ampliamente lo planteado.

Palabras clave: SOFTWARE LIBRE/ TECNOLOGÍA/ EDUCACIÓN/ DIDÁCTICA/ TECNOLOGÍA EDUCATIVA/ INTERNET/WWW/

Abstract: It is of interest for the present article the practical use of free software in the field of education; a special emphasis is given to the possibility of its use as an appropriate tool for the processes of education and learning, without avoiding its advantageous and less advantageous features, considering the contexts in which these tools are set forward. Also, practical examples of their use are given. Some news of events and recent relevant facts are included to illustrate the point of discussion in a broader sense.
\end{abstract}

Key words: FREE SOFTWARE/ TECNOLOGY/ EDUCATION/ DIDACTICS/ EDUCATIVE TECNOLOGY/ INTERNET/WWW/

\section{INTRODUCCIÓN}

En este artículo, se ofrece al lector un acercamiento general a la utilización del software libre en los procesos educativos, considerando para ello una definición y contextualización de éste último; en seguida, se ofrecerán algunas claves para entender el concepto de "tecnología educativa" y, por último, las relaciones que se establecen entre ambos, analizadas desde el punto de vista de sus consecuencias teóricas y prácticas.

A lo largo del documento, el lector encontrará referencias a direcciones de páginas http de la WWW o autores que pueden ser útiles para ampliar su comprensión de la temática. Su elaboración se logra a partir de consultas en la WWW, desde diferentes motores de búsqueda.

\footnotetext{
${ }^{1}$ Egresado del Doctorado Latinoamericano en Educación de la Universidad Estatal a Distancia UNED, Costa Rica. En la actualidad es Coordinador de la Maestría en Tecnología Educativa, del Sistema de Estudios de Posgrado de la UNED.
}

Correo electrónico: jvalverde@uned.ac.cr

Reseña recibida: 25 de abril, 2005

Aprobada: 31 de octubre, 2005 
Pero, ¿qué importancia estratégica tiene el software libre aplicado en los procesos de enseñanza y aprendizaje?

Como se explicará más adelante el discurso que usualmente se escucha en torno al software, es el de la defensa de la propiedad intelectual a ultranza, ya sea incurriendo en prácticas como el "dumping" (venta de productos a bajísimos precios para desestimular la adquisición de otros productos) o del boicoteo a organizaciones, empresas o instituciones que prueban el software libre, entre otras.

La lógica que persiste en esta línea de acciones es la de atender a los intereses privados de los sectores informáticos más poderos, solamente interesados en incrementar las ganancias, aún cuando, paradójicamente, no han sido los creadores del software, sino los que lo colocan en el mercado.

Sin embargo, si se enfocan las cosas utilizando otros puntos de vista, y se incorporan la prosperidad, el bien común y la libertad del público en general, las cosas aparecen de otro modo, pues el software libre permite disponer de herramientas para el amplio mundo de la información y la comunicación.

En este sentido, resulta estratégico apoyar, promover y divulgar el movimiento del software libre a partir de un uso extensivo, creativo y crítico en instituciones públicas, privadas, en el Estado; en fin, en buscar las formas de construir una base de trabajo no marginal, sino inmersa en la lógica de facilitar el acceso a la población de herramientas de trabajo acordes con sus necesidades y a bajo costo.

\section{SOFTWARE LIBRE}

Primero, unas precisiones en cuanto a qué interpretar por software libre y, posteriormente, qué entender por "tecnología educativa" o más precisamente: tecnologías educativas.

Por software libre se puede entender el acceso ilimitado e irrestricto a la creación intelectual en el campo de las programas destinados a las tecnologías de la información y la comunicación (en adelante TIC), donde quiera que aquella se lleve a cabo y cualesquiera sean los propósitos para los que fue pensada. 
Para que un programa se considere como software libre, se deben dar, al menos, los siguientes escenarios:

- "La libertad de usar el programa, con cualquier propósito (libertad 0).

- La libertad de estudiar cómo funciona el programa, y adaptarlo a tus necesidades (libertad 1). El acceso al código fuente es una condición previa para esto.

- La libertad de distribuir copias, con lo que usted puede ayudar a su vecino (libertad 2).

- La libertad de mejorar el programa y hacer públicas las mejoras a los demás, de modo que toda la comunidad se beneficie (libertad 3). El acceso al código fuente también es una condición previa para esto" (En: http://www.gnu.org/philosophy/free-sw.es.html).

En este sentido, cada uno de nosotros tendríamos la libertad de distribuir copias, con o sin modificaciones, a cualquier persona y en cualquier lugar. Esto supone no tener que pedir permisos o pagar por éstos ni tampoco informar de los cambios que se hacen en los programas o si éstos se publican o no.

Además, la libertad implícita en la utilización del software libre conlleva que cualquier persona o institución use los sistemas informáticos para su trabajo cotidiano, sea cual sea su naturaleza, sin informar a su creador y con acceso autónomo a los códigos fuente a los cuales se pueden realizar modificaciones para adaptarlos a las nuevas necesidades que crean su uso, experimentación y puesta en ejecución.

Libertad irrestricta en los espacios binarios: esta parece ser la señal que se le da a todos los usuarios del software libre. No obstante, esto no significa que no se lo pueda comercializar. Antes bien, un software libre debe estar disponible para su uso, desarrollo y distribución comercial, siempre y cuando quien lo adquiere tenga la libertar de copiar y modificar los programas adquiridos e, incluso, venderlos.

En el mundo de la computación, de la informática y, en general, de las TIC, para algunos resulta impensable la opción de utilizar, modificar, distribuir, entre otras posibles acciones, programas informáticos, considerando las restricciones que sus creadores imponen; se asume, como una ley incuestionable, que los poseedores de licencias son los únicos autorizados a modificar sus creaciones y que cualquier trasgresión puede ser castigada. Las leyes de propiedad intelectual son un buen ejemplo de los amparos a los que se acuden en el caso de violaciones a los programas adquiridos en el mercado. 
Sin embargo, y como se hace evidente, la aparición del software libre viene a dar una dimensión diferente a esta premisa.

Sugiero ampliar la información asociada a software libre, relacionada con algunos términos como: software de fuente abierta; software de dominio público; software protegido por copyleft; el proyecto GNU; Linux; sistema protegido por GNU; software privativo; software comercial, entre otros, visitando la siguiente página: http://www.gnu.org/philosophy/categories.es.html\#CopyleftedSoftware.

Alrededor del software libre se han originado algunas situaciones polémicas. Por ejemplo, en abierta competencia con Linux (una opción de software libre), y con el fin de mantener su mercado, la empresa Microsoft Corporation proporciona descuentos a gobiernos locales, como la Alcaldía de París, para que adquiera sus programas informáticos; lanza campañas que crean dudas sobre la legalidad o no del software libre e inclusive ofrecieron en algunos países asiáticos una versión reducida y más barata de "Microsoft XP", ante el avance de Linux en China, Tailandia, Indonesia y Malasia (amplíe este tema en: http://www.opensourceworldconference.com/modules/news/).

En Brasil, entre otros países del sur de América, se está utilizando ampliamente de software libre en instituciones gubernamentales y los resultados son exitosos, si bien todavía en proceso de evaluación.

En

http://bachue.com/colibri/listas/colibri/-3C-200306181431.h5IEVqg24317-40-

lan.hipertek.net-3E-.html, usted puede encontrar un amplio y crítico artículo acerca de la experiencia brasileña.

Actualmente, se encuentra en la Asamblea Legislativa de Costa Rica un Proyecto de Ley denominado: "Utilización de software libre en las instituciones del Estado, bajo el Expediente $\mathrm{N}^{\circ}$ 15.191. Léalo en: http://elug.ciberlinux.net/leer.php?id=8

Con este rápido panorama en torno al software libre, incorporemos a la discusión al complejo mundo de las tecnologías aplicadas a la educación o "tecnologías educativas". 


\section{TECNOLOGÍA EDUCATIVA}

Primero, hay que señalar que el concepto de tecnologías educativas remite a dos temas, de por sí heterogéneos, multivariables y polisémicos: por un lado, el que refiere a lo tecnológico y sus consecuencias en los ámbitos: socioeconómico, cultural y político y el que refiere a lo educativo, el cual involucra aspectos de índole teórica, metodológica, de planificación y curricular, entre otros.

Por los propósitos de este artículo, no se ampliará en el análisis de lo tecnológico y lo educativo por separado y se remitirá a la tecnología aplicada a la educación o "tecnología educativa".

Por tecnología educativa se entenderá la adaptación y utilización de las TIC en los diferentes momentos del proceso educativo.

Se trata de una tecnología particularmente orientada a mediar en el proceso educativo, considerando, para que sea pertinente, el contexto sociocultural e histórico en el cual se pone en marcha. Pero, además, su aplicación conlleva tomar en cuenta las etapas de diseño, ejecución, evaluación e investigación asociadas tanto a los contextos convencionales (cara a cara) como a los entornos virtuales de aprendizaje.

Según Silvia Elstein, las TIC se aplican en el campo pedagógico con el objeto de racionalizar los procesos educativos, mejorar los resultados del sistema escolar y asegurar el acceso al mismo de grupos convencionalmente excluidos (En: http://www.unrc.edu.ar/publicar/cde/Elstein.htm).

Sin embargo, y siguiendo a Elstein, es necesario que la utilización de tecnologías aplicadas a la educación se complemente con programas de capacitación y formación de los profesionales docentes, así como de una base antropológica, cultural y educativa ajustada a la realidad, con el objetivo de favorecer una intervención didáctica apropiada.

Por su parte, Fainholc concibe la tecnología educativa, desde la cultura y las mediaciones, como una práctica socio-tecnológica educativa reflexiva de intervención cultural, directamente derivada de las características específicas del aprendizaje y la enseñanza 
contextuados en escenarios culturales y con actores particulares (En: http://dewey.uab.es/pmarques/EVTE/fainholc4.doc).

En esta línea de pensamiento, se estarán propiciando ambientes de aprendizaje en los que el alumno sea capaz de interactuar con otros estudiantes y con profesores que no necesariamente están situados en el mismo medio espacial y temporal.

Es por ello que las tecnologías aplicadas a la educación involucran un reto para el sistema educativo que consiste en pasar de un modelo unidireccional de formación, donde por lo general los saberes recaen en el profesor o en su sustituto el libro de texto, a modelos más abiertos y flexibles, mediados por las TIC.

\section{SOFTWARE LIBRE COMO TECNOLOGÍA APLICADA A LA EDUCACIÓN}

Entonces, ¿cuáles podrían ser las ventajas de aplicar software libre en ambientes educativos?

El software libre puede adaptarse a las necesidades docentes; puede, por ejemplo, modificarse para ofrecer a los alumnos una versión simplificada. O darle una apariencia adecuada a los conocimientos del alumno (por ejemplo, similar a la de las herramientas con las que el alumno está familiarizado).

Si se usan programas libres, cada estudiante puede reproducir todo el entorno de prácticas, con total exactitud, en cualquier otra computadora. En particular, por ejemplo, en su casa, donde podrá practicar cómodamente. $\mathrm{Y}$ todo esto, naturalmente, sin ningún problema de licencias y sin costes extra para los estudiantes. Así, para cada curso se podría entregar un $C D$ que incluya todas las herramientas utilizadas, que se les repartiría para que saquen sus propias copias.

Además de las herramientas básicas utilizadas en el curso, es fácil y económico utilizar marginalmente otras similares, para que cada estudiante pueda experimentar con las diferencias entre herramientas parecidas. 
De hecho, los estudiantes interesados podrán utilizar una gran cantidad de programas, que se pueden incluir en el CD del curso, como complemento a las enseñanzas básicas.

Si todo el software utilizado es libre, el docente puede ponerlo a disposición de otros docentes. De esta forma se pueden preparar paquetes, disponibles mediante Internet, que incluyan la documentación y los programas usados. Así, el mismo curso podrá ser reproducido en cualquier otra parte del mundo.

En general, parece razonable que las entidades educativas, y muy especialmente las que se financian con dinero público como la UNED, no favorezcan unas empresas sobre otras.

De hecho, el favorecer a una empresa sobre otra en la educación es especialmente grave, pues da a la empresa favorecida una ventaja enorme sobre la competencia: los alumnos están formados para utilizar sus productos, y por tanto preferirán usarlos frente a los de la competencia, incluso si son peores o más caros.

Con el software libre esto no ocurre, ya que cualquier empresa puede comercializar y vender servicios para cualquier producto libre.

Como puede verse, estas ventajas del uso de software libre en el ámbito educativo no lo son sólo frente a un programa propietario dado, sino frente a cualquier programa propietario (En: http://gsyc.escet.urjc.es/ grex/sobre-libre/soft-libre-educacion.html).

Pero, ¿cuáles desventajas se pueden encontrar para el uso del software libre como tecnología educativa?

No parece haber desventajas particulares, es decir, atinentes al software libre, que sean diferentes a las que se atribuyen a cualquier tipo de software, con algunas excepciones; se pueden mencionar, entre otras:

- No tiene garantía proveniente del autor; esto es, el software libre se compra o se adquiere sin garantías explícitas del fabricante, quienes no se responsabilizan de perjuicios económicos en contra del usuario. 
- Cualesquiera modificaciones a problemas encontrados requiere de la dedicación de recursos institucionales, así como a la adaptación a las necesidades del usuario.

- Los usuarios deben tener conocimientos de programación para modificarlo y adaptarlo al contexto educativo

- También los usuarios deben estar al tanto de las modificaciones que se les haga para evitar confusiones. (Puede ver otras desventajas en: http://manifiesto.cofradia.org/libre.html)

Adicionalmente, se puede mencionar, más en el nivel general, que se debe pensar seriamente en las características específicas del software que se va a utilizar; es decir, cuán aplicable será en función de los objetivos educativos que se quieren alcanzar y su utilidad práctica en el contexto en que se pondrá en marcha y las situaciones infraestructurales, logísticas en las que podrán ser atinentes o no.

En otras palabras, la utilización del software libre como una tecnología aplicada al contexto educativo, debe llevarse a cabo teniendo en cuenta sus propiedades intrínsecas, sus posibilidades de implementación en el proceso de enseñanza y aprendizaje y el contexto social y económico que lo delimita.

Para finalizar, se pueden encontrar, entre otras, las siguientes opciones de software libre:

- Para sistemas operativos: GNU/Linux; GNU/Hurd; FeeBSD.

- Pare redes: Apache; Samba.

- Para bases de datos: PostgresSQL,; mySQL.

- Para ofimática: Openoffice; Koffice; StarOffice

Este último puede ser utilizado en educación; le invito a visitar la página http://www.cignux.org.ar/pablo.htm, en la cual se describen cada uno de sus componentes, entre los cuales se encuentran un procesador de textos, una hoja de cálculo, un módulo de base de datos, así como un módulo de creación y edición de imágenes. 


\section{REFERENCIAS ${ }^{2}$}

Brod, César. (2003). Free software in Latin America and the Caribbean. Brasil: s.n.

Himanen, Pedía. (2002). La ética del hacker y el espíritu de la era de la información. Barcelona: Destino.

Klein, Naomi. (2001). No Logo. Barcelona: Paidós.

Newman, Nathan. (1999). The origins and future of open source software. Sta. Bárbara, California: NetAction

Stallman, Richard M. (2002). Free software, free society. Bostos, Estados Unidos: GNU Press.

Vidal, Miquel. (2000). Cooperación sin mando: una introducción al software libre. Recuperado el marzo de 2005, en http://www.sindominio.net/biblioweb/telematica/softlibre/

Wayner, Peter. (2001). La ofensiva del software libre. Barcelona: Granica.

\footnotetext{
${ }^{2}$ Se incorporan estas referencias a solicitud de los editores de la revista, con el objetivo de brindar al lector otras opciones para acercarse al tema expuesto. Sin embargo, se aclara que la base documental que sirvió de sustento para el artículo, está respaldada por una búsqueda realizada en portales web accesibles por Internet, según se va indicando en el texto que usted acaba de leer 